Tabligh: Jurnal Komunikasi dan Penyiaran Islam

Volume 1, Nomor 2 (2016) 111-128

Fakultas Dakwah dan Komunikasi, UIN Sunan Gunung Djati Bandung https://jurnal.fdk.uinsgd.ac.id/index.php/tabligh

\title{
Pesan Dakwah Visual tentang Muslimah di Media Sosial Line@dakwahmuslimah
}

\author{
Siti Zakiyah Tifany ${ }^{*}$ \& Uwes Fatoni \\ Jurusan Komunikasi dan Penyiaran Islam, Fakultas Dakwah dan Komunikasi, \\ UIN Sunan Gunung Djati Bandung \\ *Email:fhany.zaky@gmail.com
}

\begin{abstract}
ABSTRAK
Artikel ini membahas pesan dakwah visual tentang muslimah dalam akun Line@dakwahmuslimah baik dari aspek konten maupun bentuk format pesan dakwah. Metode penelitian yang digunakan adalah analisis isi kualitatif dengan jenis penelitian deskriptif terhadap pesan-pesan dakwah yang diunggah akun Line@dakwahmuslimah pada bulan November 2015 sebanyak 53 pesan. Berdasarkan hasil penelitian ditemukan kategori pesan dakwah terdapat tiga, yaitu akidah, syari'ah dan akhlak. Adapun format pesan dakwah meliputi poster, meme, komik dan sticker. Dari format pesan dakwah ini ditemukan variasi konten dan format pesan dakwah visual, yaitu poster akidah, poster syariah dan poster akhlak, meme syari'ah, komik akidah, komik akhlak dan sticker akhlak.
\end{abstract}

Kata Kunci: Pesan Dakwah; Muslimah; Media Sosial; Line.

\section{ABSTRAK}

This article discusses the message of da'wah on Muslimah in the Line @ dakwahmuslimah account both the content aspect and the form format of da'wah messages. The research method used qualitative content analysis with descriptive research type of 53 messages of da'wah uploaded account Line@dakwahmuslimah in November 2015 as many as messages. Based on the research results found that there are three message categories of da'wah, namely aqidah, syari'ah and akhlak. The format of the da'wah message include posters, memes, comics and stickers. From the format of this da'wah message found variations of content and format of visual dakwah messages, namely poster on akidah, poster on syari'ah, poster on akhlak, meme on syari'ah, comics on akidah, comics on morals and stickers on akblak.

Keywords: Da'wah Message; Muslimah; Social Media; Line. 


\section{S. Z. Tifany \& U. Fatoni}

\section{PENDAHULUAN}

Kemajuan bidang komunikasi mempermudah dalam mensyiarkan dakwah Islam, sekaligus menjadikan tantangan bagi da'i. Secara sederhana dakwah dapat dipandang sebagai proses penyampaian pesan dari da'i kepada mad'u untuk selalu berada di jalan Allah, mengikuti perintah dan larangannya baik secara lisan maupun tulisan yang di dalamnya mengandung nilai-nilai ajaran Islam dengan maksud untuk menghidupkan fungsi-fungsi ajaran agama dalam kehidupan manusia. Materi dakwah menurut Samsul Munir Amin (2013: 90) dapat diklasifikasikan menjadi tiga, yaitu: akidah, syari'ah dan akhlak. Akidah adalah Akidah merupakan suatu kepercayaan untuk mengenal Allah Swt dan alam ghaib yang tidak terjangkau manusia. Akidah menurut Amin (2009: 90) hanya membahas masalah yang wajib diimani, tetapi meliputi masalah yang dilarang, misalnya syirik (menyekutukan adanya Tuhan), ingkar dengan adanya Tuhan dan sebagainya. Syari'ah menurut Ali (2012: 46) ialah aturan hidup manusia didunia yang diberikan Allah sebagai dasar hukum bagi manusia. Oleh karena itu, manusia wajib mengikuti semua ketetapan aturan Allah sesuai dengan Alquran Hadits. Akhlak menurut imam Al-Ghazali akhlak adalah daya kekuatan (sifat) yang tertanam dalam jiwa yang mendorong perbuatan-perbuatan spontan tanpa memerlukan pertimbagan pikiran (Anwar, 2010: 13).

pesan dakwah menurut Tasmara (1987: 43) merupakan semua pernyataan yang bersumber dari Alquran dan sunnah baik tertulis maupun lisan. Dalam kehidupan, manusia dalam melakukan tindakan dan aktivitas apapun tidak lepas dari Alquran dan sunnah sebagai landasan hidupnya. Dakwah dapat disampaikan oleh laki-laki maupun perempuan. Dalam hal ini penulis lebih mengkhususkan pesan dakwah yang disampaikan oleh wanita muslimah.

Wanita muslimah yang meyakini dirinya sebagai seorang muslim yang ta'at akan perintah Allah, Alquran dan sunnah sebagai landasan hidup dalam melakukan berbagai tindakan dengan hati-hati dan jeli. Menurut Nakhrawie (2007: 13) wanita sholehah sebagai mahkluk yang suci, wajib "menjaga kesucian harga dirinya dan juga dihiasi dengan akhlakul karimah. Tindakan inilah yang benar-benar mencerminkan diri sebagai seorang wanita muslimah".

Melihat teknologi pada zaman sekarang ini sudah sangat berkembang pesat, kehadiran media massa dan media komunikasi dapat 
dimanfaatkan untuk menyampaikan pesan dakwah khusunya media komunikasi dengan melalui internet. Kini dakwah tidak hanya melalui mimbar saja, tapi tetapi dapat pula melalui media sosial yang menjadi salah satu jalan untuk mensyiarkan agama Islam dengan mudah. Media sosial menurut Rulli Nasrullah (2015: 11) "media sosial adalah medium di internet yang memungkinkan pengguna mempresentasikan dirinya maupun berinteraksi, bekerja sama, berbagi, berkomunikasi dengan pengguna lain dan membentuk ikatan sosial secara virtual." Berbagai aplikasi dimedia sosial sebagai bentuk berkomunikasi, seperti Instagram, Facebook, Twitter, Line dan sebagainya.

Dengan Merebaknya situs media sosial yang muncul, hal ini dapat menguntungkan masyarakat dari berbagai belahan dunia untuk berinteraksi dengan mudah juga dengan ongkos yang lebih murah ketimbang melalui via telepon. Selain itu, dengan adanya situs jejaring sosial dapat mempercepat penyebaran informasi. Situs jejaring sosial bermacammacam bentuk dan jenisnya, salah satunya adalah Line. Line merupakan salah satu media komunikasi yang sering digunakan dan memiliki fitur- fitur yang lebih menarik. Peranan Line sebagai media komunikasi sedikit banyaknya telah mempengaruhi pengguna untuk mensyiarkan agama Islam melalui unggahan foto atau gambar dan video. @dakwahmuslimah adalah salah satu akun yang penulis teliti terkait pesan-pesan dakwahnya dalam media sosial Line.

Line merupakan sebuah aplikasi yang digunakan untuk bertukar informasi pesan baik berbentuk teks, video, audio dan gambar secara gratis dengan menggunakan jaringan internet sebagai media atau alat pengirim pesan. Aplikasi line ini bisa digunakan oleh semua jenis smartphone atau komputer. Selain fungsinya untuk mengirim pesan, line memiliki fitur-fitur menarik dalam pengiriman pesan, sehingga line dikenal banyak orang dengan stickernya. Dengan adanya sticker pengguna lebih mudah dalam mengekspresikan dirinya baik ketika senang, sedih dan sebaginya dengan menggunakan sticker tersebut.

Sejarah berdirinya Line ini menurut Putra (2014: 82) mulai muncul ketika terjadi tsunami dan gempa besar yang terjadi di Jepang pada tahun 2011. Saat itu, karyawan NHN terpaksa harus berhubungan melalui internet antar satu sama lain, kemudian NHN memutuskan membuat aplikasi yang bisa diakses dan mudah digunakan melalui smartphone, tablet dan desktop untuk melakukan instant messaging secara gratis yang disebut Line. Saat itulah line resmi digunakan pada tanggal 23 Juni 2011 oleh NHN cabang 


\section{S. Z. Tifany \& U. Fatoni}

Jepang. Pada bulan November 2012 pengguna Line mencapai 74 juta diseluruh dunia, kemudian pada tanggal 2 mei 2013 angka pengguna semakin meningkat hingga 150 juta, Negara-negara pengguna Line ini berada di Asia termasuk Indonesia. Salah satu cara perusahaan mendapatkan keuntungan yaitu dengan menjual sticker virtual yang bisa dikirim saat chating. (Putra, 2014:83). Menurut Puskakom (2014:5) jumlah pengguna Line di Indonesia pada tahun 2014 sudah mencapai lebih dari 10 juta pengguna, termasuk peningkatan penjualan tablet atau smartphone yang digunakan oleh pengguna di Indonesia. Salah satu akun Line yang cukup diminati karena mengandung pesan-pesan dakwah yaitu akun Line (a) dakwabmuslimab.

Penelitian ini mengungkapkan apa saja isi pesan dakwah dan format serta konten pesan dakwah yang di unggah pada bulan November 2015 dengan bertujuan untuk mengungkapkan isi pesan yang terkandung di dalam akun Line@dakwabmuslimah.

\section{METODE PENELITIAN}

Penelitian yang digunakan menggunakan analisis deskriptif kualitatif, yaitu untuk meneliti pada kondisi objek yang alamiah, menekankan pada isi dari suatu informasi baik berupa teks, gambar atau simbol. Dalam penelitian ini instrumennya adalah orang atau peneliti itu sendiri juga metode ini digunakan untuk mendapatkan data yang mendalam, suatu data yang mengandung makna (Sugiono, 2012: 8-9).

Penelitian ini merupakan penelitian analisis isi kualitatif, yaitu penelitian yang lebih menekankan pada isi suatu informasi baik berupa pesan teks, gambar atau simbol. Dengan metode inilah peneliti dapat memecahkan masalah dengan memaparkan secara detail objek yang diteliti, apa saja isi pesan dakwah dan format serta konten pesan dakwah yang di unggah pada bulan November 2015 dengan bertujuan untuk mengungkapkan isi pesan yang terkandung di dalam akun Line @)dakwahmuslimah.

Teknik pengumpulan data dilakukan dengan observasi, yaitu mengamati pesan dakwah yang diposting dalam akun@dakwahmuslimah, wawancara yang dilakukan pada para admin@dakwabmuslimah yaitu Ustadz Rizqi Awal dan Erina Ahdiani, dan dokumen media atau arsip dimana dapat melihat isi dari sebuah teks dan makna yang dipublikasikan melalui media sosial.

Teknik analisis data ini membuat dua kategori pesan yaitu konten 
pesan dakwah dan kategori format pesan dakwah, serta gabungan dari kedua pesan tersebut. Setelah itu, kategori tersebut diuji dengan menggunakan lembar koding analisis isi antara peneliti dengan Fithria Khusno, mahasiswi UIN Bandung dengan menggunakan rumus analisis isi yaitu untuk mengetahui berapa yang disetujui dan tidak disetujui.

\section{DAN PEMBAHASAN}

(a) dakwahmuslimah merupakan salah satu nama akun media sosial yang di daftarkan Akbar Nazary Muhammad sekaligus sebagai founder dari @dakwahislam. Tepat bulan Maret 2015 Akbar memutuskan membuat sebuah akun media sosial yang bertujuan untuk melakukan dakwah Islam yang dikhususkan kepada para muslimah.

(a)dakwahmuslimah ini berada dalam naungan@dakwabislam. Pada mulanya Akbar membuat akun@dakwahislam, dimana tujuan dakwahnya selain amar ma'ruf nabi munkar (berbuat baik dan melarang yang buruk) juga untuk memperkuat ukhuwah Islamiyah (tali persaudaraan antar umat Islam). Kemudian Akbar membuat kembali akun media sosial @ dakwahmuslimah yang dikhususkan hanya untuk wanita muslimah. Selain Akbar Nazary ada beberapa admin yang ikut andil dalam membantu menyebarkan dakwah diakun @dakwahmuslimah, diantaranya Rizqi Awal dan Erina Ahdiani. Berikut hasil wawancara dari para admin melalui via sms atau chat pada tanggal 27 Januari dan 13 Mei 2016 mengenai profil admin.

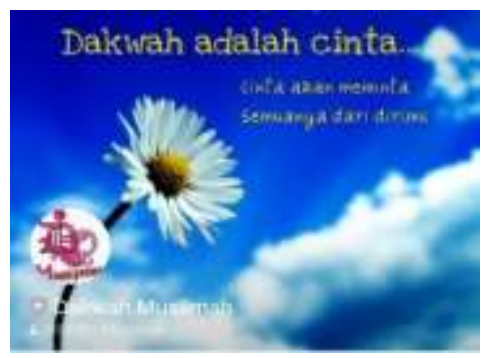

Gambar1Halaman Awal Akun@dakwahmuslimah

Profile picture yang digunakan@dakwahmuslimah di setiap media sosial sebagaimana gambar 1 dengan gambar wanita dengan bertuliskan muslimah, dengan tujuan memberi arti bahwa apa yang diunggah akun (a)dakwahmuslimah membahas tentang berbagai macam pesan dakwah yang dikhususkan untuk wanita muslimah dengan kemasan yang unik dan jelas. Dalam halaman profile@dakwahmuslimah memiliki tagline yaitu 


\section{S. Z. Tifany \& U. Fatoni}

"dakwah adalah cinta, cinta meminta semuanya darimu".

Menurut Erina, salah satu admin@dakwahmuslimah menjelaskan maksud dari tagline di atas melalui hasil wawancara, yaitu cinta pasti akan meminta apapun, selayaknya mencintai seseorang. Kita rela melakukan apapun untuk orang yang kita cintai. Jadi pada intinya kita mampu mejadikan dakwah sebagai sesuatu yang kita cintai. Karena dakwah itu cinta, maka perhatian, waktu, harta bahkan nyawa kita rela berikan untuk dakwah dijalan Allah Swt.

Kini akun@dakwahmuslimah berkembang menjadi sebuah kegiatan dakwah rutinan yang diselenggarakan oleh para admin, selain berdakwah dimedia sosial. Akbar selalu membuat kajian rutinan dengan memberitahukan kepada jamaah melalui akun

(a) dakwahmuslimah mengenai hari dan jam kegiatan. Selain itu, @ dakwahmuslimah menjadi wadah kontribusi, dimana followers atau mad'u dapat berbagi pendapat, artikel Islami atau pesan dakwah lainnya pada akun @ dakwahmuslimah. Dalam proses pembuatan dan penyebarannya tentu para admin bebas dan memiliki hak masing- masing untuk update konten pesan, tetapi jika pesan itu bersumber dari luar maka admin wajib menyertakan nama penulis dari setiap pesan yang diunggah, baik dari internet atau dari jama'ah. Beberapa pesan yang bersumber dari jama'ah atau internet seperti@alfiburaiyah,@aybumaeni,@imammuslimamin, Ustadz Fuad Hamzah, IslamPos dan santri kalong.

Line dapat dijadikan sebagai media untuk berdakwah, karena melihat perkembangan teknologi komunikasi media sosial Line saat ini banyak dipakai oleh penduduk dunia. Termasuk Indonesia, saat kemunculan aplikasi Line tahun 2011 hingga saat ini memiliki perkembangan pesat. Line memiliki banyak kelebihan pada saat pengguna akan memakai aplikasi Line. Diantaranya adalah menggugah foto dengan keunikannya menggunakan emoticon, para pengguna diberikan kebebasan dalam memberikan keterangan tulisan berupa ide dan gagasan.

Line menjadi sasaran yang tepat untuk dijadikan sebagai media dakwah, dengan memanfaatkan perkembangan teknologi penyampaian pesan dakwah melalui Line relatif terjangkau baik dari segi ruang dan waktu. Dalam berinteraksi antara pemiliki akun (Da'i) dengan pengikut akun (mad'u) dapat terjadi secara langsung. Karena, di media sosial Line diberikan ruang interaksi antara pemilik akun dengan pengikut akun. Sampai saat ini banyak sekali admin media sosial Line yang dimanfaatkan sebagai media dakwah. Berikut kategori pengguna akun Line sebagai 
berikut: (1) Akun Line@dakwahmuslimah dijadikan sebagai kategori pesan dakwah. Akun ini aktif dalam menggunakan Line sebagai media dakwah, setiap harinya pesan dakwah yang disampaikan 5 sampai 10 pesan yang diunggah sehingga hal ini banyak diminati oleh kaum wanita muslimah. (2) @beraniberhijrah. Akun ini dibuat oleh Aldilla D wijaya. Pesan-pesan yang disampaikan berifat umum, khususnya untuk mengajak mad'u kembali pada Jalan yang diridhoi Allah (berhijrah). (3) @) kartunmuslimah memanfaatkan media Line untuk menyampaikan dakwah dengan kemasannya yang unik, yaitu dengan gambar kartun sebagai media penyampaian pesan dakwah dengan diberi kata-kata sesuai dengan gambar kartun tersebut.

Berdasarkan para pengguna Line di atas bisa diketahui bahwa media sosial Line memberikan alternatif bagi para da'i untuk memanfaatkan media sosial sebagai media dakwah. Dakwah melalui media sosial merupakan cara baru yang lebih kreatif sesuai dengan perkembangan teknologi saat ini, yaitu dengan dikemas secara unik dengan menyisipkan teks, gambar atau foto sebagai konten pesan dakwah tanpa mengurangi esensi pesan dakwah sesuai ajaran Islam yang bersumber dalam Alquran dan Hadits.

\section{Konten Pesan Dakwah Akun Line@dakwahmuslimah}

Analisis pesan dakwah yang dikaitkan dengan pesan dakwah tentang muslimah pada akun @dakwahmuslimah menggunakan metode analisis isi kualitatif dengan pendekatan deskriptif. Menurut Eriyanto (2011:47) analisis isi dimaksudkan untuk menggambarkan secara detail suatu pesan atau aspek dan karakteristik dari suatu pesan.

Bulan November 2015 dalam akun@dakwahmuslimah terdapat 53 pesan-pesan dakwah tentang muslimah di media sosial Line. Adapun hasil analisis pesan dakwah dalam akun@dakwahmuslimah dengan dibagai pada tiga kategori yaitu akidah, syari'ah dan akhlak dapat dilihat pada tabel dibawah ini:

Tabel 1 Kategori Pesan Dakwah

\begin{tabular}{llc}
\hline Tgl & Tema Pesan & $\begin{array}{c}\text { Kategori } \\
\text { Pesan }\end{array}$ \\
\hline 6 Nov & Video M. Al-Fatih & Akidah \\
9 Nov & Kehidupan kedua di akhirat & Akidah \\
1 Nov & Bidadari dunia tidak bersayap tapi berhijab & Syari'ah
\end{tabular}


S. Z. Tifany \& U. Fatoni

\begin{tabular}{|c|c|c|}
\hline $4 \mathrm{Nov}$ & Kewajiban menutup aurat & Syari'ah \\
\hline $7 \mathrm{Nov}$ & Do'a agar tidak sedih & Syari'ah \\
\hline $17 \mathrm{Nov}$ & Anjuran bangun malam & Syari'ah \\
\hline $20 \mathrm{Nov}$ & Memohon pertolongan Allah & Syari'ah \\
\hline $21 \mathrm{Nov}$ & Haramnya pacaran & Syari'ah \\
\hline $26 \mathrm{Nov}$ & Kewajiban berhijab & Syari'ah \\
\hline $26 \mathrm{Nov}$ & Do'a pagi dan sore & Syari'ah \\
\hline $28 \mathrm{Nov}$ & Hanya untuk ibadah & Syari'ah \\
\hline $29 \mathrm{Nov}$ & 5 perbuatan wanita berzina & Syari'ah \\
\hline $30 \mathrm{Nov}$ & Alasan enggan berhijab & Syari'ah \\
\hline $1 \mathrm{Nov}$ & Kewajiban memilih suami karena agamanya & Akhlak \\
\hline 3 Nov & Pembakaran masjid oleh oknum & Akhlak \\
\hline $3 \mathrm{Nov}$ & Sabar atas ujian Allah & Akhlak \\
\hline $4 \mathrm{Nov}$ & Tips suami makin makin cinta & Akhlak \\
\hline $5 \mathrm{Nov}$ & Sedekah :donasi untuk anak negeri” & Akhlak \\
\hline $6 \mathrm{Nov}$ & Video pejuang Islam M. Al-Fatih & Akhlak \\
\hline $10 \mathrm{Nov}$ & Nasehat ayah mencari ilmu & Akhlak \\
\hline $11 \mathrm{Nov}$ & Saat wanita lain memikat hati & Akhlak \\
\hline $12 \mathrm{Nov}$ & Kisah 4 ekor binatang & Akhlak \\
\hline $13 \mathrm{Nov}$ & Meminta adalah hal yang dibenci Allah & Akhlak \\
\hline $13 \mathrm{Nov}$ & Nikah nunggu mapan & Akhlak \\
\hline $14 \mathrm{Nov}$ & Nama-nama anak penuh berkah & Akhlak \\
\hline $14 \mathrm{Nov}$ & Pejuang Islam Shalahuddin Al-Ayubi & Akhlak \\
\hline $15 \mathrm{Nov}$ & Korban anak peperangan di Suriah & Akhlak \\
\hline $17 \mathrm{Nov}$ & orang lalai memilih harta daripada keluarga & Akhlak \\
\hline $17 \mathrm{Nov}$ & Kefanatikan terhadap Negara & Akhlak \\
\hline $17 \mathrm{Nov}$ & Nasehat ayah mencari teman hidup karena Allah & Akhlak \\
\hline $17 \mathrm{Nov}$ & Media bungkam saat muslim ditikam & Akhlak \\
\hline $18 \mathrm{Nov}$ & Perbaiki diri untuk bekal akhirat & Akhlak \\
\hline $18 \mathrm{Nov}$ & Perbaiki diri untuk pasangan terbaik & Akhlak \\
\hline $20 \mathrm{Nov}$ & Menahan amarah, bagimu surge & Akhlak \\
\hline $21 \mathrm{Nov}$ & Jangan marah ketika hujan datang & Akhlak \\
\hline $22 \mathrm{Nov}$ & $\begin{array}{l}\text { Wanita shalihah tidak takut nikah karena } \\
\text { miskin harta }\end{array}$ & Akhlak \\
\hline $23 \mathrm{Nov}$ & Gambar bayi Noor dari Irak & Akhlak \\
\hline $23 \mathrm{Nov}$ & Andai Paris adalah Palestina & Akhlak \\
\hline $23 \mathrm{Nov}$ & Aturan Islam istri ingin bekerja & Akhlak \\
\hline $24 \mathrm{Nov}$ & Pierre Vogel, mantan petinju Jerman & Akhlak \\
\hline $24 \mathrm{Nov}$ & Wanita Palestina ditembak militer Yahudi & Akhlak \\
\hline $24 \mathrm{Nov}$ & Aku bangga jadi seorang muslim & Akhlak \\
\hline $24 \mathrm{Nov}$ & Jangan awasi orang lain, tapi diri sendiri & Akhlak \\
\hline $24 \mathrm{Nov}$ & 3 nasehat semut kepada Nabi Sulaeman AS & Akhlak \\
\hline $24 \mathrm{Nov}$ & Ibu, jangan doakan anak ketika marah & Akhlak \\
\hline
\end{tabular}


Pesan Dakwah Visual tentang Muslimah di Media Sosial Line @dakwahmuslimah

$\begin{array}{lll}25 \mathrm{Nov} & \text { Terimakasih guruku } & \text { Akhlak } \\ 26 \mathrm{Nov} & \text { Kewajiban berhijab } & \text { Akhlak } \\ 27 \mathrm{Nov} & \text { Wanita sholehah jadi perhiasan dunia } & \text { Akhlak } \\ 27 \mathrm{Nov} & \text { Istri itu pendamping bukan pembantu } & \text { Akhlak } \\ 27 \mathrm{Nov} & \text { Teman yang membawa kebaikan } & \text { Akhlak } \\ 28 \mathrm{Nov} & \text { Pantaskan diri lebih baik } & \text { Akhlak } \\ 29 \mathrm{Nov} & \text { Terimkasih murid kepada guru } & \text { Akhlak } \\ 30 \mathrm{Nov} & \text { Bersyukur bantuan Indonesia pada Gaza } & \text { Akhlak } \\ 30 \mathrm{Nov} & \text { Penderitaan wanita Palestina } & \text { Akhlak } \\ 30 \mathrm{Nov} & \text { Kisah penjual ikan } & \text { Akhlak }\end{array}$

Berdasarkan tabel 1 kategori pesan dakwah akidah atau yang berkaitan dengan masalah keimanan muslimah terdapat 2 pesan. Pesan dakwah yang berhubungan dengan syari'ah atau masalah keislaman terdapat 11 pesan dan kategori terakhir yaitu masalah budi pekerti atau akhlak terdapat 42 pesan. Dari ketiga kategori pesan dakwah diatas, jumlah yang paling banyak ada pada masalah akhlak. Akhlak menjadi hal paling utama yang harus dimiliki oleh semua orang khususnya seorang muslimah. Karena hal ini berhubungan dengan perilaku akhlak seorang muslimah kepada orang lain, baik dan buruknya seseorang dalam Islam dilihat dari sumber Alquran dan Hadits.

\section{Format Pesan Dakwah Ak in Line @dakwahmuslimah}

Salah satu format pesan menurut Nasrullah (2015: 126) adalah meme. Meme merupakan aspek visual dan teks yang menjadi bentuk format dalam sebuah media. Sedangkan poster menurut Hidayat (2014: 696) merupakan media yang menyajikan informasi dalam bentuk visual gambar, selain poster dan meme peneliti menambahkan dua kategori yang termasuk pada format pesan dakwah visual, yaitu sticker dan komik. Dapat dilihat berdasarkan tabel berikut:

Tabel 2 Kategori Format Pesan Dakwah

\begin{tabular}{lll}
\hline Tgl & \multicolumn{1}{c}{ Tema pesan } & Kategori format \\
\hline 1 Nov & Bidadari dunia tidak bersayap tapi pasti berhijab & Poster \\
1 Nov & Kewajiban memilih suami karena agamanya. & Poster \\
3 Nov & Sabar terhadap ujian Allah & Poster \\
4 Nov & Tips agar suami makin cinta & Poster \\
5 Nov & Sedekah "donasi untuk anak negeri” & Poster \\
6 Nov & Kisah perjuangan raja Islam M. Al-Fatih & Poster \\
7 Nov & Do'a agar tidak sedih & Poster
\end{tabular}

Tabligh: Jurnal Komunikasi dan Penyiaran Islam Vol. 1 No. 2 (2016) 111-127 
S. Z. Tifany \& U. Fatoni

10 Nov Nasehat ayah mencari ilmu untuk ibadah Poster

11 Nov Saat wanita lain memikat hati Poster

12 Nov Kisah 4 ekor binatang Poster

13 Nov Meminta hal yang dibenci Allah Poster

13 Nov Nikah nunggu mapan Poster

14 Nov Nama-nama anak penuh berkah Poster

14 Nov Pejuang Islam Shalahuddin Al-Ayubi Poster

15 Nov Korban anak peperangan Suriah Poster

$17 \mathrm{Nov}$ Anjuran bangun malam Poster

17 Nov Nasehat orang yang lalai Poster

$17 \mathrm{Nov}$ Mencari suami karena Allah Poster

17 Nov Media bungkam saat muslim ditikam Poster

18 Nov Perbaiki diri untuk bekal akhirat Poster

18 Nov Perbaiki diri untuk dapat pasangan terbaik Poster

20 Nov Memohon pertolongan Allah Poster

20 Nov Menahan amarah bagimu surge Poster

21 Nov Jangan marah kala hujan datang Poster

21 Nov Haramnya pacaran Poster

22 Nov Wanita sholehah tidak takut nikah miskin harta Poster

23 Nov Bayi Noor dari Irak Poster

23 Nov Andai Paris Palestina Poster

23 Nov Aturan Islam ketika bekerja Poster

24 Nov Pierre Vogel mantan petinju Poster

24 Nov Wanita Palestina ditembak Yahudi Poster

24 Nov Aku bangga jadi muslim Poster

$24 \mathrm{Nov}$ Jangan mengawasi orang lain Poster

$24 \mathrm{Nov} 3$ nasehat semut pada Nabi Sulaeman as Poster

$24 \mathrm{Nov}$ Risalah Ibu jangan mendoakan anak ketika marah Poster

25 Nov Terimakasihguru Poster

26 Nov Do'a pagi dan sore Poster

26 Nov Kewajiban berhijab Poster

27 Nov Dua pilihan wanita sholehah Poster

27 Nov Istri itu pendamping bukan pembantu Poster

27 Nov Jadilah teman membawa kebaikan bukan keburukan Poster

28 Nov Memantaskan diri jadi lebih baik Poster

28 Nov Hanya untuk ibadah Poster

29 Nov 5 perbuatan wanita dicatat zina Poster

30 Nov Kisah penjual ikan Poster

30 Nov Penderitaan wanita Palestina Poster

30 Nov Asalan enggan berjilbab Poster

4 Nov Kewajiban menutup aurat Meme

3 Nov Pembakaran masjid hanya oknum Komik

9 Nov Kehidupan kedua diakhirat Komik

17 Nov Kefanatikan Negara Komik

120 Tabligh: Jurnal Komunikasi dan Penyiaran Islam Vol. 1 No. 2 (2016) 111-127 
29 Nov Terimakasih murid pada guru

Sticker

30 Nov Terimakasih bantuan muslim Indonesia pada Gaza Sticker

Berdasarkan tabel 2, jumlah format meme 1 pesan, format komik ada 3 pesan, format sticker ada 2 pesan dan format poster ada 47 pesan.

Pertama, Format pesan dakwah berbentuk poster. Poster Pesan dakwah ini dapat digunakan sebagai media untuk kepentingan dakwah. Karena, kini pesan dakwah tidak hanya disampaikan dalam bentuk komunikasi secara langsung tetapi dapat disampaikan melalui media visual seperti poster dengan kombinasi gambar, warna dan kata-kata lebih mudah menarik perhatian orang untuk melihatnya. Sehingga pesan-pesan dakwah yang terdapat di dalamnya pun terlihat lebih hidup dan memberikan kesan yang mendalam pada pembaca atau mad'u.

Dalam format pesan dakwah poster dibagi pada dua kategori, yaitu poster gambar dan poster kartun. Berdasarkan temuan jumlah format poster gambar sebanyak 45 pesan, dan jumlah format poster kartun berjumlah 2 pesan. Yaitu format poster gambar dan format poster meme.

Format poster gambar sebagai bentuk untuk menyampaikan informasi atau pesan kepada orang yang melihat atau membaca poster tersebut. Salah satu contoh bentuk poster gambar yaitu:

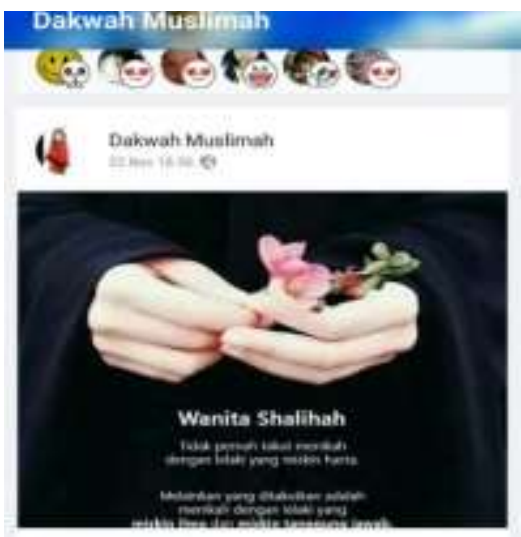

Gambar 2 Poster Gambar (1 Nov 2015)

Poster gambar di gambar 2 menjelaskan bahwa wanita shalihah dengan menggunakan kerudung hitam hingga menjulur ke bawah sampai pergelangan tangan. Warna hitam ini menandakan seorang wanita sederhana dalam berpakaian juga sebagai pelindung bagi dirinya, sebagaimana di ungkapkan Lia dan Kirana (2014:38) bahwa "warna Tabligh: Jurnal Komunikasi dan Penyiaran Islam Vol. 1 No. 2 (2016) 111-127 


\section{S. Z. Tifany \& U. Fatoni}

hitam merupakan warna yang kuat, penuh percaya diri, penuh perlindungan, elegan dan misterius". Kemudian ditambah bunga berwarna pink muda sebagai tanda kelembutan dan keindahan dari dirinya sebagai wanita sholehah. Juga ditambah bentuk teks bahwa "wanita sholehah tidak takut menikah karena miskin harta, tetapi lebih takut menikah karena miskin ilmu". Tulisan tersebut sebagai penguat dari gambar wanita sholehah.

Format kedua adalah format poster kartun. Menurut Supriadi (2008:2) kartun adalah sebuah gambar dengan tulisan singkat dan sederhana, menggunakan simbol serta karakter agar mudah dikenal, dipahami oleh pembaca dan kuat dalam ingatan dalam menerima pesan atau informasi. Salah satu contoh bentuk poster kartun yaitu:

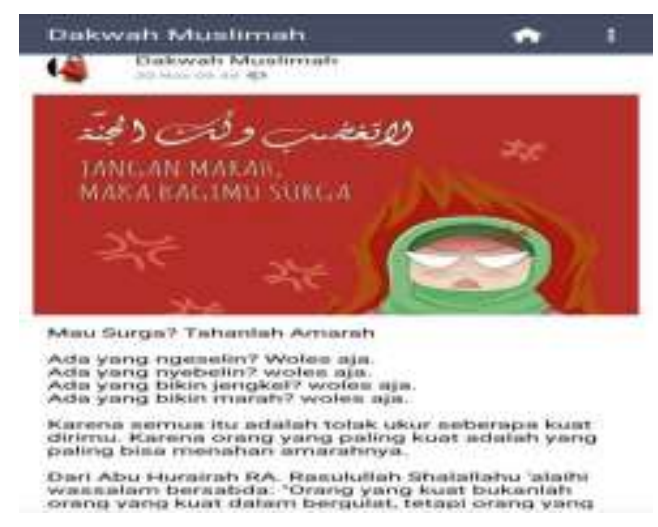

Gambar 3 poster gambar kartun dan teks (20 Nov 2015)

Berdasarkan gambar di gambar 3, bentuk format dari gambar kartun tersebut berekspresi wajah yang sedang marah atau emosi, mata yang lebar dan melotot, kemudian dikelilingi gambar api sebagai bentuk kemarahan, baground merah yang menandakan dirinya sedang benar-benar marah, sebagaimana dikatakan oleh Kirana (2014:38) bahwa warna merah memiliki kekuatan emosional, cenderung ekstrim, penuh kekuatan dan berbahaya. Hal ini serupa pada gambar kartun tersebut.

Selain itu, ditambah dengan menggunakan hijab berwarna hijau sebagai tanda perlindungan bagi diri seorang wanita muslimah untuk melindungi dirinya dari sikap marah, ditambah bentuk tulisan sebuah hadist yaitu "jangan marah maka bagimu surga". Hadist ini sering diungkapkan di dalam acara pengajian-pengajian, sehingga ketika diberikan ekspresi 122

Tabligh: Jurnal Komunikasi dan Penyiaran Islam Vol. 1 No. 2 (2016) 111-127 
dengan gambar ini semakin memperkuat pesan bahwa seseorang itu khususnya muslimah dilarang untuk marah dan menahan hawa nafsu.

Kedua, format pesan dakwah berbentuk meme. Meme merupakan media visual yang menggunakan teks dan gambar sebagai bentuk penyampaian pesan, biasanya meme ini bersifat hiburan, sindiran, dan kritikan sebagai ciri dari meme tersebut. Kategori pada format pesan meme hanya ada satu yaitu pada tanggal 3 November 2015. Bentuk gambarnya dapat dilihat dibawah ini:

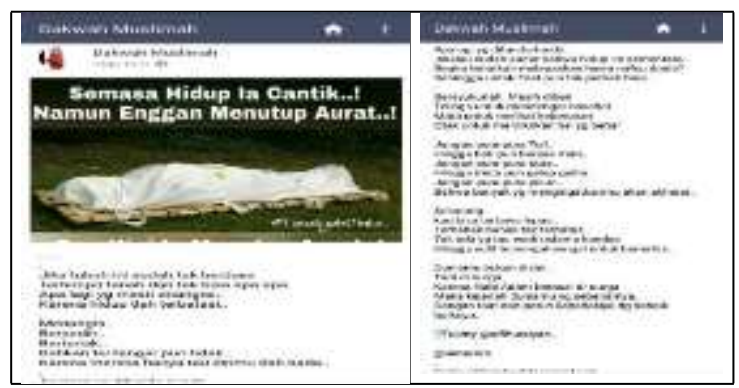

Gambar 4 Format Meme (4 Nov 2015)

Poster meme di gambar 4 secara singkat memberikan pesan kepada pembaca dengan ditambah gambar orang yang telah meninggal dan ditutup kain kafan berwarna putih. Menurut Adi (2007:47) warna putih ini memiliki arti ketakutan, misteri, kematian dan ketidakbahagiaan. Hal ini, serupa dengan gambar diatas yang menandakan kematian. Selain itu juga, rumput hijau dan tanah yang menunjukan seolah berada dipemakaman. Kain kafan ini mengisyaratkan bahwa seorang wanita muslimah harus selalu mengingat kematian, semasa didunia seorang muslimah wajib mengikuti perintah Allah untuk menutup aurat sebelum ia ditutupi kain kafan seperti gambar diatas. sesuai dengan isi pesan yang ada pada gambar tersebut yaitu "sulit untuk ta'at pada perintah Allah" sebagai penguat dari meme diatas yang mewajibkan kepada wanita muslimah untuk menutup aurat.

Ketiga, format pesan dakwah visual komik. Komik adalah gabungan antara gambar dengan tulisan yang disusun secara kreatif (Fatoni, 2014). Menurut Adi (2007:164) komik adalah rangkain gambar yang disusun berdasarkan alur cerita yang disampaikan. Penggunaan gambar tersebut mampu menarik perhatian orang lain juga dapat lebih mudah dipahami. 


\section{S. Z. Tifany \& U. Fatoni}

Pesan dakwah komik berjumlah 3 pesan dan ketiganya termasuk pada komik yang isinya hanya berupa satu tampilan yang terdiri dari gambar dan tulisan.

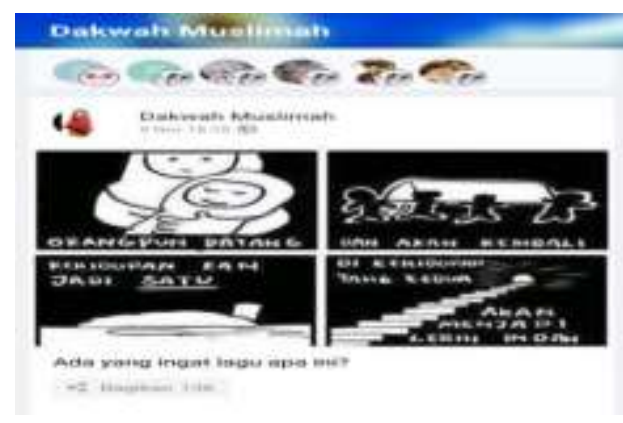

Gambar 5 Format Komik (9 Nov 2015)

Gambar komik di gambar 5 menjelaskan kepada pembaca khususnya wanita muslimah, yaitu terdapat rangkaian cerita dalam gambar hitam putih, yaitu hitam menggambarkan kegelapan dan putih menandakan kesucian atau kematian. Gambar seorang ibu yang menggendong anaknya seakan menandakan orang datang atau mengawali hidup di dunia, kemudian gambar kedua ada keranjang dibawa oleh orang- orang yang menandakan orang yang hidup akan merasakan mati dan kembali dikubur lalu melewati tangga-tangga sebagai jalan untuk menuju surga. Hal ini, sebagaimana menurut Supriyono (2010:78) bahwa warna hitam dan putih ini termasuk pada dimensi warna terang-gelap (value), yaitu menggabungkan antara warna terang dengan gelap untuk menciptakan kemudahan dalam membaca pesan atau informasi.

Keempat, format pesan dakwah visual sticker. Sticker adalah sebuah gambar orang dengan bentuknya yang unik dan lucu. Menurut Putra (2014: 87)"Sticker adalah sebuah fitur dimana terdapat sebuah gambar emotikon orang dengan ekspresi yang lucu dan menggemaskan. Berikut tabel dibawah ini sebagai format pesan dakwah kategori sticker. format pesan sticker gambar berjumlah 2. Berikut salah satu contohnya: 


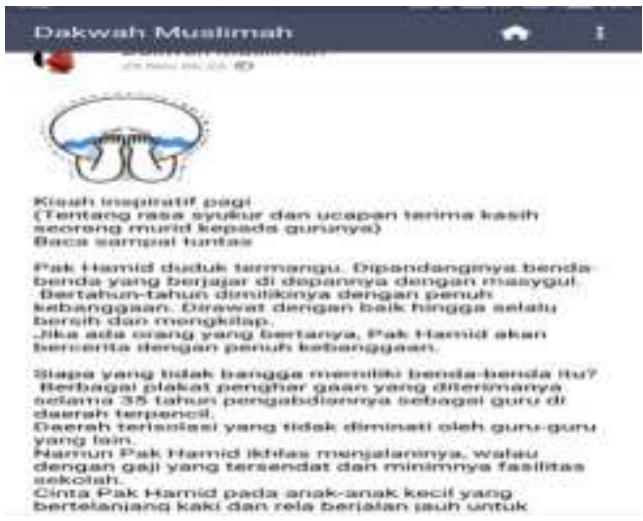

Gambar 4 Format Sticker (29 Nov 2015)

Bentuk sticker di atas yaitu gambar orang lucu dan menggemaskan, dengan mengekspresikan wajah sedang menangis dengan air mata berwarna biru yang mengalir deras, sebagaimana diungkapkan Lia (2014:38) bahwa warna biru ini tidak bisa lepas dari elemen langit, air, udara, menggambarkan keharmonisan dan kesetiaan. Selain itu ditambah mata tertutup dan kedua tangan menutup pipi, dikelilingi tanda titik diatas kepala yang menunjukan orang tersebut benar-benar sedang dalam keadaan sedih atau terharu. Pesan yang ada pada gambar diatas "rasa terimakasih untuk jasa guru-guruku" sebagai pelengkap dan penguat dari sticker tersebut.

Melihat pembahasan konten dan format. Maka itu bisa diketahui dengan isi pesan dakwah berdasarkan dua kategori tersebut ditemukan poster akidah (1 buah), poster syariah (10 buah), poster akhlak (36 buah), meme syariah (1 buah), komik akidah (1 buah), komik akhlak (2 buah), dan sticker akhlak (2 buah).

Berdasarkan temua di atas, jumlah poster akhlak paling banyak muncul, yaitu 36 buah. Ini terjadi karena pesan-pesan akhlak disampaikan dalam bentuk gambar, dianggap bisa memberikan kekuatan pengaruh yang lebih besar, dibandingkan hanya sekedar melalui pesan- pesan verbal atau pesan tulisan.

\section{PENUTUP}

Berdasarkan hasil penelitian dapat ditarik kesimpulan, dalam akun @ dakwahmuslimah bulan November 2015 pesan dakwah pada akun 


\section{S. Z. Tifany \& U. Fatoni}

(a)dakwahmuslimah di media sosial Line dapat diketahui, pertama, kategori konten pesan dakwah dalam akun Line@dakwahmuslimah terdiri atas 3 kategori yaitu akidah, syari'ah dan akhlak. Pesan akidah yaitu pesan iman kepada Allah dan iman kepada hari akhir. Pesan syari'ah yaitu kewajiban menutup aurat, anjuran menjauhi zina dan anjuran beribadah. Pesan akhlak yaitu akhlak suami istri, akhlak kepada keluarga, anjuran melakukan akhlak terpuji dan larangan melakukan akhlak tercela. Kedua, kategori format pesan dakwah visual dalam akun Line (a)dakwahmuslimah ada 4 kategori yaitu poster gambar dan poster kartun, meme sindiran, komik dan sticker. Dari format pesan dakwah ini maka bisa ditemukan variasi konten dan format pesan, yaitu poster akidah, poster syari'ah dan poster akhlak, meme syari'ah, komik akidah, komik akhlak dan sticker akhlak.

Penelitian ini masih harus disempurnakan untuk itu saran disampaikan kepada pengelola akun@dakwahmuslimah, dalam menyajikan pesan dakwah harap lebih memperhatikan isi pesan, terutama lebih banyak berkaitan dengan fiqih karena masalah fiqih ini masih kurang diperhatikan oleh para muslimah dalam kehidupan sehari-hari. Demikian juga kepada para muslimah diharapkan bisa lebih memahami pesan-pesan yang ada dengan cara memperkuat literatur berkaitan pesan tersebut, selain itu juga mempraktekkan pesan-pesan tersebut dalam kehidupan sehari-hari, sehingga bisa didapatkan hasil atau buah dari pesan-pesan tersebut. Adapun kepada para peneliti selanjutnya, diharapkan dapat mengkaji penelitian lebih lanjut mengenai pesan dakwah di media sosial Line dari aspek yang lain, seperti pengaruh kepada pembaca, aspek semiotika dan sebagainya.

\section{DAFTAR PUSTAKA}

Amin, S. M. (2009). Ilmu Dakwah. Jakarta: Amzah.

Enjang AS. \& Aliyudin. (2009). Dasar-dasar Ilmu Dakwah. Bandung: Widya Padjajaran

Eriyanto. (2011). Analisis Isi. Jakarta: Kencana Prenada Media Group

Fakultas Dakwah dan Komunikasi. (2013). Panduan Penyusunan Skripsi Fakultas Dakwah dan Komunikasi. Bandung: Fakultas Dakwah dan Komunikasi UIN SGD Bandung.

Fatoni, U. (2014). Media Dakwah Alternatif. Republika, 29 Maret 2014.

Nathalian K., \& Anggraini, L. (2014). Desain Komunikasi Visual, Bandung: Nuansa Cendekia 
Supriyono, R. (2010). Desain Komunikasi Visual, Yogyakarta: C.V Andi Offset

Nasrullah, R. (2015). Media Sosial. Bandung: Simbiosa Rekatama Media

Amin, S. M. (2013). Ilmu Dakwah. Jakarta: Amzah.

Sugiono, (2012). Metode Penelitian Kuantitatif Kualitatif dan R\&D. Bandung: Alfabeta

Tim Pusat Humas Kementerian Perdagangan RI. (2014). Panduan Optimalisasi Media Sosial Untuk Kementerian Perdagangan RI. Jakarta: Pusat Hubungan Masyarakat

Tasmara, T. (1987). Komunikasi Dakwah. Jakarta: CV Gaya Media Pratama Pramiyanti, A., Christin, M. (2014). Makna Simbol Emotikon Dalam Komunitas Kaskus, Jurnal Sosioteknologi 13(2).

Benny A. (2016). Modul Latiabn Pengertian dan Perkembangan Konsep Media Pembelajaran. Diakses 20 Mei 2016. http://belajar.kemdikbud.go.id 